\title{
Wellness Tourism: Using Tourists' Preferences to Evaluate the Wellness Tourism Market in Jamaica
}

\author{
Nadine Angelita Valentine ${ }^{a^{*}}$ \\ a MSc Tourism \& Hospitality Management, The University of the West Indies, Mona Campus. \\ ${ }^{*}$ Corresponding author's email addresses: nadine.valentine02@gmail.com, wellnessstudyjamaica@gmail.com
}

\section{A R T I C LE IN F O}

Received: 00-00-0000

Accepted: 00-00-0000

Available online: 00-00-0000

Keywords:

Nadine Valentine

Wellness tourism

Wellness preferences

Wellness tourism in Jamaica

Rural tourism

Nature -based tourism

JEL Classification:

\section{A B S T R A C T}

This study sought to evaluate the general wellness preferences of tourists in Jamaica as there is little information to support the body of knowledge on these tourists' wellness preferences in Jamaica and to successfully facilitate segmentation in the wellness tourism market. Jamaica has a naturally appealing environment however; performance in wellness tourism is not among its competitive strengths. Tourists have aligned themselves with the existing tourism offering. A framework is therefore needed to align the push factors of tourists' wellness expectations with the pull factors of tourism's offerings. The research examined the tourists' socio - demographic profile, their travel characteristics and the importance of wellness to them. Additionally, it investigated preferred amenities and services, the natural resources associated with particular accommodations, the type of accommodations preferred for a wellness vacation and the locations' attractive attributes. Pre tested survey instruments were randomly administered to two hundred tourists awaiting departure from the island's two international airports. SPSS (version 22) was used to test frequency distributions and percentages, statistical significance and internal consistency. The finding shows that wellness was important however, young people, retirees and higher income earners were not well represented. Strong preferences exist for natural remedies, wellness competencies and mind therapies. Low preferences exist for culinary tours, mineral baths, community involvement and nature experiences. Despite the location's reported physical attractiveness, hotels were preferred for a wellness vacation and many natural and historic features were unexplored. The findings imply that the unique wellness preferences may facilitate 'new forms' of tourism and non seasonal tourism niches for small businesses, hotels and rural communities. There may be an alignment with the vocational training system, tourism marketing efforts and international standards. Infrastructural development may also be facilitated around naturally occurring springs, heritage sites, historical buildings and unexplored natural highlights. This emphasis will subsequently support workplace wellness and primary health care.

(C) 2016 The Authors. This is an open access article under the terms of the Creative Commons Attribution License 4.0, which allows use, distribution and reproduction in any medium, provided the original work is properly cited.

DOI: http://dx.doi.org/10.18533/rss.v1i3.16

This study aims to evaluate the wellness preferences of tourists in Jamaica. This aspect of tourism is one of two components of health tourism and it has become an important area of focus for the Vision 2030 Jamaica, National Development Plan. Destination competiveness is not guaranteed because of the island's unique assets (C. Chen, S. H. Chen, \& Lee , 2011) however, the findings of this study may assist in the development of a much 
needed framework to align the push factors of tourists' wellness preferences with the pull factors of the services and amenities of hotels and wellness providers.

\subsection{The statement of problem}

The data that are generally available focuses more on the marketing and positioning of spa wellness services and facilities. In addition, high quality evaluation studies provide little information supporting the body of knowledge on the wellness preferences of tourists in Jamaica. Additionally, there is no evidence that evaluating tourists' preferences will successfully facilitate segmentation in the wellness tourism market.

\subsection{The purpose of the study}

The study's seeks to establish the importance that broad profiles of tourists assign to wellness services and amenities. It also ventures to ascertain whether tourists' wellness preferences are similar to those associated with the available natural resources in Jamaica and whether these assets may facilitate the development of niche markets. Presently, there is no distinction between wellness services supporting nature based product and those supporting a spa based product.

An emerging issue among stakeholders is the view that policymakers do not fully appreciate the economic benefits of wellness and that standard and practices are needed in the industry. Additionally, some have argued that Jamaica's current vocational training system should align itself with that of recognized international certification programmes (Sheldon\& Park, 2008).

A national policy for wellness tourism in Jamaica is also lacking and, there has been no differentiation between Jamaica and other Caribbean destinations and/or Latin-American destinations Caribbean Spa and Wellness Strategy (2014-2018). The technical report of the Jamaica Health and Lifestyle Survey (2007- 2008) also indicates that performance in wellness tourism was not among Jamaica's competitive strengths; in addition much is yet to be discovered about opportunities that can move the country to a higher level.

\subsection{The concept of wellness}

The ambiguity surrounding the concept of wellness has been challenged as scholars including e.g. Dunn, Ardell, Travis and Benson, Stuart and Greenberg and Dintman and Hertel have provided varying definitions of wellness (Brown, Howat, and Voigt, 2010; Meuller and Kaufmann, 2001) conceptualizes wellness as the sum of all the relationships resulting from a journey by tourists whose primary motive is to maintain or promote their health and well-being and who stay at least one night at a facility that is specifically designed to enable and enhance physical, psychological, spiritual and/or social well-being.

To arrive at an understanding of wellness tourism in the sector, Figure 1 provides a demarcation to match guests' expectations of guests with the supply of appropriate services.

\section{Figure 01: A demarcation for wellness tourism}
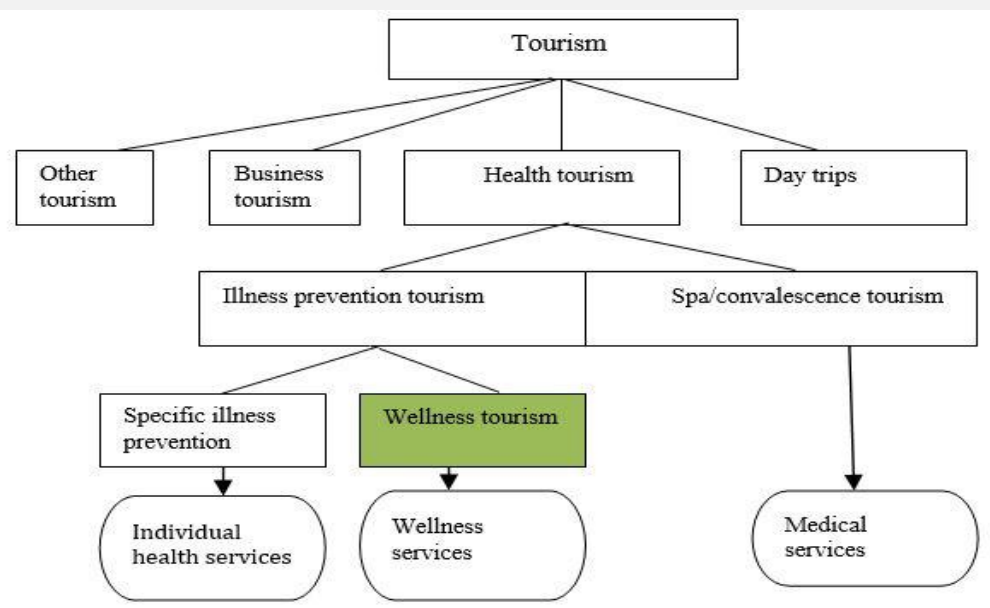

Source: Journal of Vacation Marketing, Volume 7 Number 1 (Meuller and Kaufmann, 2001) S 5-17 
In examining how the approach to this topic is evolving, this study investigates the concept of 'new tourism', the Resource Based View (RBV) from the perspective of the firm's perspective and ways in which these ideologies may facilitate different tourism niches in Jamaica.

\subsection{The organization of the study}

This introduction has provided a short overview of the importance of wellness tourism in Jamaica, the overall purpose of the paper and the circumstances surrounding this topic. The background will provide an overview of the industry's profile, the arguments in favour of wellness tourism in Jamaica and the Caribbean and the challenges facing the region's wellness tourism market. Additionally, it will examine the research questions, the research objectives and some concepts relating to wellness tourism. The literature review will have a thematic and geographical approach as it will investigate motivations and preferences from a global perspective. In this regard, it will examine the attributes of nature-based tourism in the Jamaican context and compare it with the tourism product dominated by spa services .The methodology section will introduce the research design, the participants, the method of data collection and the data analysis. The results section will present the findings in relation to the general preferences in Jamaica .The discussion will facilitate a comparative analysis of national and global trends in wellness preferences. Additionally, it will present expected and unexpected results to ascertain whether the findings addressed Jamaica's strengths. The conclusion will highlight the responses to the research questions and the implications of the study. Recommendations will be made for tourism stakeholders and for future research. The research project will conclude with an alphabetical listing of all cited sources.

\subsection{The background}

The global market for health and wellness is estimated to generate approximately US $\$ 106$ billion annually (table 1) and wellbeing tourism is increasingly popular.

Bloomberg Business Week validates this demand by estimating the US wellness market at approximately US $\$ 400$ billion Caribbean Spa and Wellness Strategy (2014-2018) with 54\% of travellers choosing spa vacations.

The demand for wellness vacations is growing worldwide popularity as the Baby Boomers have now retired (Gorodinia et al., 2012); many of these retirees have opted for service providers that can satisfy their desires for self-transformation (Brown et al., 2010). Jamaica's Vision 2030 report (2010) has also confirmed that the travellers in the 16-24 years age groups are strong prospects for marketing and promotion, as they are gradually replacing the Baby Boomers and Generation X (Cohen , Moital \& Prayag ,2014). The spa and wellness sector in Caribbean Forum of African, Caribbean and Pacific States (CARIFORUM) countries is underdeveloped compared with that of Asia, Europe and the United States.

Table 01: Contributions from the health and wellness sub- sectors

\begin{tabular}{lr} 
Sub Sectors of Health and Wellness & Contribution \$US \\
\hline Spa & $\$ 60 \mathrm{~B}$ \\
\hline Complementary and Alternative Medicine & $\$ 113 \mathrm{~B}$ \\
\hline Healthy Eating/Nutrition/Weight Loss & $\$ 277 \mathrm{~B}$ \\
\hline Preventative/Personalized Health & $\$ 243 \mathrm{~B}$ \\
\hline Wellness Tourism & $\$ 106 \mathrm{~B}$ \\
\hline Medical Tourism & $\$ 50 \mathrm{~B}$ \\
\hline Workplace Wellness & $\$ 31 \mathrm{~B}$ \\
\hline Fitness and mind-body & $\$ 390 \mathrm{~B}$ \\
\hline Beauty and anti-aging & $\$ 679 \mathrm{~B}$ \\
\multicolumn{2}{c}{ Source: Caribbean Spa and Wellness Strategy 2014-2018, July 2013 } \\
\multicolumn{2}{|c|}{}
\end{tabular}

\subsection{Wellness tourism in the Caribbean}

The Caribbean has competitive advantages in that most countries are in close proximity to major areas of demand that have rich ethnic diversity and legacies of healing and health practices Caribbean Spa and Wellness Strategy (2014-2018). The sector, though underdeveloped, boasts over twenty world class spas Caribbean Spa and Wellness Strategy (2014-2018) and wellness tourism is estimated to generate at $\$ 106$ billion annually (Table 1) Caribbean Spa and Wellness Strategy (2014-2018). In terms of the infrastructure, the Caribbean Spa and Wellness report has indicated that wellness in CARIFORUM countries have been challenged by few purpose built facilities and the lack of established standards and the ideal ambiance Caribbean Spa and Wellness Strategy, (2014-2018). The report proposes strong mitigation measures and recommends the following: 
- establishing a policy and regulatory framework that will realise the adaptation of best practices

- strengthening of the capacity and professional resources

- developing a comprehensive marketing strategy

- improving the product and the capacity of sector operators

\subsection{Wellness tourism in Jamaica}

Through its Service Sector and Expansion Plan, JAMPRO (2013)) aims to capture at least 1\% of the global wellness tourism market. Within the next five years, it seeks to achieve an annual income of US70 million. In formulating its outline of the country's plans for development status by 2030, the National Development Plan also expects to increase market demand and profitability, as wellness tourism is not heavily reliant on the regular tourist seasons (Metapirak \& Siriphannapirat, 2012). Wellness Tourism has been identified as a window of opportunity, as travellers increasingly seek for meaningful experiences beyond the traditional offerings of Jamaican vacations (Obradović, 2007).

Jamaica has taken advantage of the market trends (Gorodinia et al. 2012) which is among the arguments in favour of wellness tourism on the island. Jamaica's Economic and Social Survey (2013) reported an increase in stopover by cruise passengers between 2003 and 2013 with over $80 \%$ of passengers taking tours every month during this period. A Trip Advisor survey (2007) report an increased need for 'holiday experiences' compared to an "active holiday" as there are now fewer travel barriers and cheaper air travel (Vision 2030 Jamaica, 2010). In its 2013 progress report, JAMPRO also reported an increase in wellness treatments and experiences at large spas in luxury hotels, all-inclusive resorts, boutique hotels, private villas and day spas across the island. The 2009 Tourism and Travel Index ranked Jamaica $60^{\text {th }}$ of 133 travel destinations Vision 2030 Jamaica, 2010) with positive rankings in policy rules and regulation, the prioritization of travel and tourism strategies and the strong interest in travel and tourism. Jamaica therefore holds a competitive position because of its appealing natural environment, brand image and human and cultural assets (Vision 2030 Jamaica, 2010). There are also strong appeals for the Jamaican cuisine, the rich cultural heritage (Vision 2030 Jamaica, 2010) and strong all inclusive hotel brands. The supply characteristics, shows that the country already possesses the push factors of supply; however creating a framework that can align these push factors with the pull factors of demand will be challenging.

\subsection{The strengths of Jamaica's natural resources}

A review of the literature has revealed that there is a strong demand from the source markets for eco- tourism (Vision 2030 Jamaica, 2010). Jamaica has an extensive biodiversity in the Cockpit Country and the Negril Royal Palm Reserve. The island also has an outstanding seascape and landscape with potential to observe wild life, to visit natural attractions in the Blue and Johncrow Mountain National Park, marine parks in Negril, Montego Bay and Ocho Rios, museums, animal parks, heritage sites, the Hope Zoo and to explore mountain ranges and hiking trails. There is also rich topography and geography as the island boasts many rivers and waterfalls many of which have strong historic connections (Vision 2030 Jamaica, 2010). Regarding wellness amenities, activities and services, most hotels reportedly have tennis courts and gym facilities, outdoor recreation, green spaces, facilities for fishing and marine, bird watching and water sports (Vision 2030 Jamaica, 2010).

Jamaica is purportedly strongly predisposed for nature -based experiences. Presently, there is no distinction between wellness attributes aligned with mass tourism and those aligned with slower wellness tourism niches. Tourism planners and facilitators are expected to use these findings to coordinate and encourage communitybased tourism particularly in the rural areas and to market other potential niches such as heritage tourism and culinary tourism. Such strategies are particularly important for small and medium sized enterprises that have low levels of occupancy as they may be able to capitalize on the existing natural resources, scenic landscapes and nature -based assets in their surroundings. Wellness practitioners are also expected to benefit as they seek to adapt best practices in wellness service that are aligned with source market demand. The findings are also expected to influence national certification programmes in vocational institutions and universities as well as marketing and communication efforts (Brown et al.2010). Therefore, this paper seeks to determine how the country's natural resources can best be purposefully aligned with the push and pull factors (Chen et al., 2014).

\subsection{Research questions}

The following quantitative questions are addressed:

1. How important is wellness to tourists in Jamaica?

2. How important are wellness amenities and services to tourists in Jamaica? 
3. Do tourists in Jamaica have a strong preference for nature -based tourism?

4. What preferred natural resources are aligned with Jamaica's geographical location?

5. Which of the location's wellness attributes are attractive to tourists in Jamaica?

\subsection{The conceptual framework}

"New tourism" is a concept that is associated with Jamaica's Tourism Master Plan (Vision 2030 Jamaica, 2010). The concept which evolved from the World Travel and Tourism Council (2003) mandates that governments consider tourism a priority and collaborate in a way that benefits people, culture and the environment. Conway and Timms (2010), mention examples of 'new forms of tourism'- eco-tourism, heritage tourism and communitybased tourism - that will help with rebranding wellness tourism, improve local conditions and cater to an authentic experience.

\subsection{The role of the customer in the service experience}

The Resource Based View (RBV) is a business management philosophy that advocates the use of a firm's resources to gain competitive advantage. This concept, relates to the tourist's role as a customer (Gorodinia et al.2012). However, the tourist also serves as a productive resource, a co marketer and a co-designer and wellness providers are advised to listen to his/her opinions.

\subsection{Literature review}

In highlighting the importance of this research topic, Brown et al. (2010), have shown that ample ambiguity surrounds the terminologies associated with wellness. 'Wellness tourism' 'health tourism', 'well-being tourism', 'holistic tourism' and 'spa tourism' have been used interchangeably.

\subsection{Current wellness trends}

The identified wellness trends are expected to improve competitiveness among smaller hotels in Jamaica particularly those with European Plans. This expectation becomes justifiable as the industry is changing to offer holidays that caters less to physical needs and more to emotional and spiritual needs (Ravichandran \& Suresh 2010). In North America, the number of persons who wish to look and feel better has significantly increased. Additionally, there is a demand for wellness programmes that will improve fitness levels, healthy lifestyle education, nutrition counselling, complementary and alternative practices and other therapies.

The Travel and Research Handbook 2013 - 2014 Caribbean Spa and Wellness Strategy (2014-2018) shows that many hotel chains are rebranding themselves around wellness and that meal options are being customized around gluten free and vegetarian options. Massage therapy is trending towards a "mindfulness" massage that allows for body works that engages every part of the body in a mind transforming experience.

The $10^{\text {th }}$ Annual Trends Analysis Finder Wellness also identifies a shift from a manufacturing to a service economy. The concept of "earthing" is being used to provide people with real contact with nature and to reduce what is described as the "Nature Deficit Disorder". The wellness seeker is encouraged to make barefoot contact with the earth's surface such that the natural electric rhythm facilitates "grounding" to the earth surface and reduce the incidence of inflammatory diseases. This report also highlighted the possibility of incorporating lifestyle changes into the wellness experience, such that diseases can be halted by changing the impressionable part of the DNA or telomere. Studies are confirming that benefits may be derived through Spa -Genomics in which the telomeres are repaired through stress reduction, sleep, exercise, healthier eating and mediation. The re-emergence of ancient rituals is also trending as these rituals provide an authentic experience and incorporate more age old wellness traditions. Wellness facilities are also trending towards locations on ancient sites and within reclaimed historical buildings with ancient architectural designs. The Publication, Healing Sources: Spa and Wellbeing from the Baltic to the Black Sea (Benge, 2014, www.amazon.com), makes reference to the healing culture in Europe which highlights the region's architecture, food, natural remedies, history and fascinating characters. Other trends in Europe includes the pit sauna in Latvia, respiratory healing in the salt mines of Poland, mineral therapy waters in Hungary, smoke sauna in Estonia and mud pools in Slovakia. In addition, colour is increasingly used as a form of self-expression. The industry has also been trending towards 'an inclusive wellness' that caters to all ages, physical abilities and body types. Increasingly, this shift includes services such as pampering, pain relief, improved mobility and functionality especially for those with special needs. The use of the expression 'Label Conscious Fitness' has increased and refers to customised fitness labels configured as brands to fit any fitness preference. Spas are also trending towards "for-men beauty" particularly 
for the male client who needs face and body enhancement. The report concludes that there is an increasing need for more skilled wellness professionals.

\subsection{Tourists' general wellness preferences and motivators}

In Thailand, tourists have a strong preference for Thai herbs with an emphasis on natural Eastern approaches to treatment. The success of Thailand's wellness tourism product has been attributed to its culture, healing traditions and scenic location Caribbean Spa and Wellness Strategy (2014-2018). India's wellness product has been associated with spirituality with several of its spas being built around luxurious palaces that have been converted to hotel chains Caribbean Spa and Wellness Strategy (2014-2018). Its marketing efforts have also focused on its considerable offerings in Ayurveda, yoga traditions, meditation, vegetarianism, other healing practices and cultural life in the Indian home. India's success has been attributed to its investment in the wellness sector, adaptation of best practices and specialization Caribbean Spa and Wellness Strategy (20142018). Consequently, it attracts many wellness tourists from the West who seek to strengthen their spiritual health. Ravichandran and Suresh (2010) believe that India's success can be attributed to its rebranding efforts.

A study of spa goers in Hong Kong (Pesonen and Komppula (2010) shows that among the important motivators for spa wellness are physical relaxation, pampering, personal reward, an escape from work, peace and overall health improvement. The study also shows that spa goers could be divided based on their preferred benefits including those associated with hedonists, escapists or neutralists. A similar study in Korea shows that tourists were motivated by relaxation away from the ordinary ( Mak et al.2009).

A study in Switzerland saw the establishment of guests into four categories; demanding guests who required care, information, professional competence, comprehensive wellness amenities and a swimming pool. Independent infrastructure users who required wellness facilities and a swimming pool; care intensive guests who required healing, therapy, convalescence, medical competence, health promotion, individual care and advice and undemanding recreation guests who required relaxation, recreation and a swimming pool (Meuller \& Kaufmann, 2001). Asia reportedly has the advantage of a beautiful exotic landscape (Heung \& Kucukusta, 2013).

In assessing Jamaica's spa facilities, JAMPRO (2013) verifies that there were 40 independent boutique spas in Kingston and 20 in the other resort areas. Additionally, there were 25 main hotel destination spas and wellness centres in the larger hotels and approximately 15 in other establishments. Jamaica has naturally occurring spas including those in Rockfort, Milk River, Bath and Black River; however, these spas reportedly offer services mainly to the small local market.

Jamaica's local spas are presently staffed by those trained locally at HEART Trust NTA School of Cosmetology and through the Northern Caribbean University (NCU) Spa Management Programme. However, the Tourism Product Development Company (TPDCO) has led the way in the development of standards now adopted by the Jamaica Bureau of Standards. The Service Sector Strategy and Expansion Plan JAMPRO (2013) also indicated that massages, fitness, stress management, nutrition and cosmetic treatments were among the popular spa services. There is also scope for complementary and alternative therapies such as homeopathy, chiropractic, weight loss and fitness services, assisted living and elderly care.

\subsection{Tourism preferences for rural tourism}

Rural tourism is among the newer forms of tourism which Pesonen and Komppula (2010) describe as a form of well-being associated with small family enterprises and lifestyle entrepreneurship. In essence, rural tourism falls outside of densely populated areas and tourism centres (Pesonen \& Komppula, 2010). Those interested in this form of tourism seek opportunities for relaxation, a calm atmosphere, an attractive landscape, family togetherness, and opportunities for children, friendly reception, healthy meals, independence and flexibility. However, according to Pesonen and Komppula (2010) this choice of holiday depends on the respondents' background and not on associations in the city or on price.

Given the seemingly symbiotic relationship between rural tourism and nature-based characteristics. Gorodinia et al. (2012) argue that marketing efforts should focus on Jamaica's, beautiful natural setting and its unspoiled landscape.

\subsection{Jamaica's cultural and heritage tourism product}

In examining the perceptions of cultural and heritage tourism, Brown et al. (2010) claim that not enough attention has been given to tourism segments that are now requiring more than sea sand and sun. They argue 
that more consideration should be given to health and wellness through hot springs and spas and that culture should be highlighted through heritage sites and galleries. Surveys have shown that many tourists want to see more of Jamaica than what exists within the walls of hotel properties (Brown et al. 2010). In her thesis on Cultural Tourism in Jamaica, Pitter (2005) is of the view that cultural tourism would benefit from an integrative approach that includes health, sports, adventure tourism and eco-tourism. She argues that the all-inclusive concept inhibits community tourism and detracts from the businesses of local and small entrepreneurs (Pitter, 2005). The researcher likens this approach to a trickledown effect. Rural tourism has been a hallmark in many countries (Pesonen \& Komppula, 2010) and enhances the culture and heritage of the rural destination and the relevance of anthropology in tourism.

In comparing Jamaican and Japanese heritage Francis-Lindsay (2009) highlights cultural and heritage tourism as the most successful tourism niche and argues that developing countries have focused more on economic benefits than on making its population more culturally aware. In assessing the issues surrounding rural tourism, the SWOT analysis of Vision 2030 Jamaica of National Development Plan contends that heritage tourism is not expanding in rural Jamaica. The number of tourists visiting heritage events has been low because they were often held in rural settings that could not accommodate tourists. Francis-Lindsay likens this to "cultural decay" while the Tourism Development Plan (Vision 2030 Jamaica, 2010) likens it to ignorance on the part of communities that may not know how to capitalise on heritage events. Eco sites and education among locals about the positive attributes of the environment are areas that were targeted for strengthening. FrancisLindsay's study continues by highlighting the high value that Europe has placed on cultural heritage, even though it lacks the luxury generally associated with wellness. Pesonen and Komppula (2010) also believe that Jamaica would benefit socially, culturally and economically if the population were better equipped.

Jamaica has several natural and therapeutic mineral springs (Pesonen \& Komppula, 2010). Francis Lindsay alludes to the scenic geographical landscape which includes limestone formation, mountains, plateaus, plains, caves, sinkhole, stalagmites and stalactites, underground streams and pools, harbours, bays, mangroves, swamps coral reefs, black and white sand beaches, and numerous rivers cascading into waterfalls however Chen et al., (2011) supports the view that destination competiveness is not guaranteed because of a location's unique assets. In terms of historicity, Falmouth Jamaica is described as one of the Caribbean's best preserved towns with Georgian infrastructure (Francis-Lindsay, 2009). This town has been listed among the 100 most endangered sites.

\subsection{Summary}

In summary, the review of the literature provides a global perspective, supporting the view that the global economies are trending towards service rather than manufacturing. There is an increasing trend towards earthbased features, the adaptation of age-old traditions and practices and historic locations. Products and services are no longer geared towards those with a wellness disposition but towards different socio-demographic and economic groups. The affluent and youth markets are being targeted globally as markets with travellers who are willing to pay for customized experiences. Among experiences in demand, the literature mentions yearlong spa experiences, spa communities and destinations catering to the spiritual, mental, physical and emotional wellbeing.

The literature highlighted the lack of a major distinction between Caribbean and Latin American destinations. Nevertheless, the Caribbean, because of its proximity to the source market and the strength of its nature-based resources stood to benefit from careful planning, policy development, the strengthening of capacity, professional resources, infrastructure improvements, community involvement and marketing strategies. The literature also emphasizes nature- based tourism, complementary and alternative therapies and amenities for different categories of tourists based on the level of freedom or personal care. Additionally, Jamaica reportedly has strengths related to eco-tourism and heritage tourism but they are underdeveloped because of a lack of participation and buy-in among Jamaicans. Standards are also being developed by major tourism stakeholders who recognise that the system of vocational training needs to be aligned with internationally certified systems.

In terms of general preferences, global trends tend towards spa vacations with staff, room quality, housekeeping, food and beverage and family togetherness listed among the top preferences. Other preferences include wellness programmes, lifestyle education and counselling. The most important niches are reportedly those affiliated with culture, historicity and authentic practices unique to the destination, which facilitates return visits. Preferences for nature- based wellness experiences differ somewhat from those of spa goers. Preferences include family togetherness social interaction, a scenic environment and, in some cases an unspoiled location. Attractive attributes include the pursuit of multiple activities, recreation, affordability and opportunities for socialization. The nation's strategic plans emphasize the relevance of mineral baths, eco-sites 
and heritage events; however despite the country's natural beauty and resources, nature-based tourism has not been adequately developed. However, in evaluating the tourists' preferences, the study has generally identified the natural resources that are aligned with the different parishes.

\subsection{Methodology}

\subsection{The research design}

The study of wellness tourism is relatively new in Jamaica; therefore an exploratory method was used with quantitative research methods. To facilitate responses to the research questions the survey instrument was structured to address questions that were critical to the research objectives.

\subsection{Population and sampling}

The study was cross - sectional and the data collection instruments were interviewer -administered. The respondents were randomly selected and the target population included tourists' who were awaiting departure from the Norman Manley International Airport in Kingston and the Donald Sangster International Airport in Montego Bay after a stay in Jamaica. Tourists' leaving Jamaica were chosen as participants because they represented a primary data source that could provide responses about their visitor experience during their stay in Jamaica. The sampling frame used was cluster sampling and the sample size of $200(n=200)$ was derived based on the Jamaican population and on the sample size used in a similar study by Meuller \& Kaufmann, 2001).

\subsection{Instrumentation}

The questions were designed to measure wellness motivators, attitudes towards wellness, wellness preferences, wellness expectations, the importance of wellness amenities and the physical aspects of the vacation experience. In an introductory note, the respondents were advised of the purpose of the survey and were invited to participate based on established research protocol. Section one captured demographic data, including age group, gender and country of origin; section two sought responses regarding the respondents' reasons for travel; section three aimed to ascertain the respondents' current lifestyle as it relates to health and wellness; section four surveyed respondents regarding 25 wellness expectations which were measured on a 5- point Likert scale ranging from (1) not at all important to (5) very important. The measurements reflected tourists' perceptions and attitude regarding health as it pertains to amenities, treatments, service quality, and aspects of the location, the accommodation and the attractiveness of the location. Finally, section six sought to establish socio- economic parameters by assessing the tourists' the length of stay, employment status and gross salary as well as descriptions of those who accompanied them to Jamaica. The questionnaire was pre-tested among 20 guests at the Mona Visitors' Lodge and Conference Centre in Kingston, Jamaica.

\subsection{Data collection}

This study used random sampling and the research instrument was a four-page questionnaire with 16 questions. Questions regarding some wellness preferences were customized questions, concerning the respondents' sociodemographic were derived from tourism related survey instruments and from studies by Meuller \& Kaufmann, 2001 ; Pesonen\& Komppula, 2010. The data were collected and generated in an acceptable for research. Only trained interviewers from the Jamaica Tourist Board were asked to administer the survey instrument because access to departing visitors at the airports was prohibited as the airport was considered a sterile environment for students. The questionnaires were administered between 20 April 2015 and 1 May 2015, during the latter, less hectic phase of the winter tourist season. One hundred and fifty questionnaires were administered in Montego Bay the port of call for five of six of the resort areas while 50 questionnaires were administered in Kingston. The participants included males and females from different geographical locations. Two hundred questionnaires were completed with $100 \%$ response rate.

\subsection{Research hypothesis}

Research question 1 - How important is wellness to tourists in Jamaica?

Research Hypothesis 1- Wellness is very important to tourists in Jamaica.

Research question 2-How important are wellness amenities and services to tourists in Jamaica?

Research Hypothesis 2 - Wellness services and amenities are very important to tourists in Jamaica. There is a relationship between the respondent's' age and the importance placed on wellness amenities and services. 
Research question 3-Do tourists in Jamaica have a strong preference for nature-based tourism? Research Hypothesis 3 - Tourists in Jamaica do not have a strong preference for nature- based tourism.

\subsection{Variables}

The data set included variables that were potentially useful for further study. A frequency distribution was performed on all variables while Pearson's chi square was used for the cross tabulation of respondents' age and attitude to wellness, types of accommodation preferred for a wellness vacation and the parishes in which they were located, preferred physical attributes and their alignment with the geographical location.

\subsection{Data analysis}

The Statistical Package for the Social Sciences SPSS (version 22) was used for data analysis. Univariate analysis and bivariate analyses were conducted for frequency distributions and percentages while Cronbach's alpha statistics were used to measure the internal consistency for the 25 questions used for the evaluation (table 4) and to confirm whether the sample of questions (question 6.1 - 25) were actually unidimentional. The test resulted in a maximum alpha of 0.90 to 0.91 and fell within the stipulated range. (Dennick \& Tavakol, 2011). The test of reliability was 0.91 . The index of measurement error was 0.18 , i.e. $(0.91 \times 0.91=0.82,1.00-0.82=0.18)$. The test reliability of a test score attributable to error decreased as the estimates of reliability increased which validated this finding (Dennick \& Tavakol, 2011). A confidence interval of $95 \%$ and an error of $+2 \%$ was used. This output from both analyses would facilitate a comparison of the percentages across categories and, describe the pattern/direction of association for rows while the overall table would determine the statistical significance.

To increase the reliability, validity and objectivity of this research, source triangulation was used; the researcher designed the questionnaire using research instruments associated with the discipline and a thorough interrogation of the literature. Theoretical triangulation was employed to justify the tourism trend leading to wellness tourism while instructor triangulation was used via consultations.

\subsection{The results and discussion}

\subsection{Profile of wellness tourists}

The results from the socio-demographic profile are expected to add to the knowledge base as it seeks to ascertain the feasibility of meeting the demand of the affluent tourist, the youth and retirees as well as the general preferences of those in the source market. Table 2 presents data on the demographic characteristics of the respondents showing an almost equal distribution of males (42 per cent) and females (58 per cent). The number of retirees was comparatively lower (6 per cent) and younger tourists represented 32 per cent of the sample. Most visitors fell into the lower income bracket (under US\$25,000 per year and those visiting from the source market represented 92 per cent of the sample. Gorodinia, Lester and Pearcy (2012) put forward the view that wellness tourists are not always price sensitive and that many will pay a high price for luxury spa services.

Table 2 also shows that most tourists fell within the 35 to 49 age group (34 per cent); followed by those in the 50 to 64 age group (28 per cent) and those in the 25 to 34 age group were 23 per cent. The youth market i.e. tourists' ages 24 years and younger, represented 8 per cent of the tourists while retirees, i.e. age 65 years and older represented 6 per cent.

The results also showed that most tourists were visiting from the United States (38 per cent) with similar proportions from Europe and Canada (27 per cent respectively); only 3 respondents were visiting from the Caribbean. Most respondents had fulltime employment, (59 per cent) while there were almost equal proportions of students and retirees (11 per cent). The result for the potential youth market (24 years and younger) was low compared with that for the 24 to 35 age group. The findings for retirees, those in the higher income were also low when considering a potential target market of the affluent.

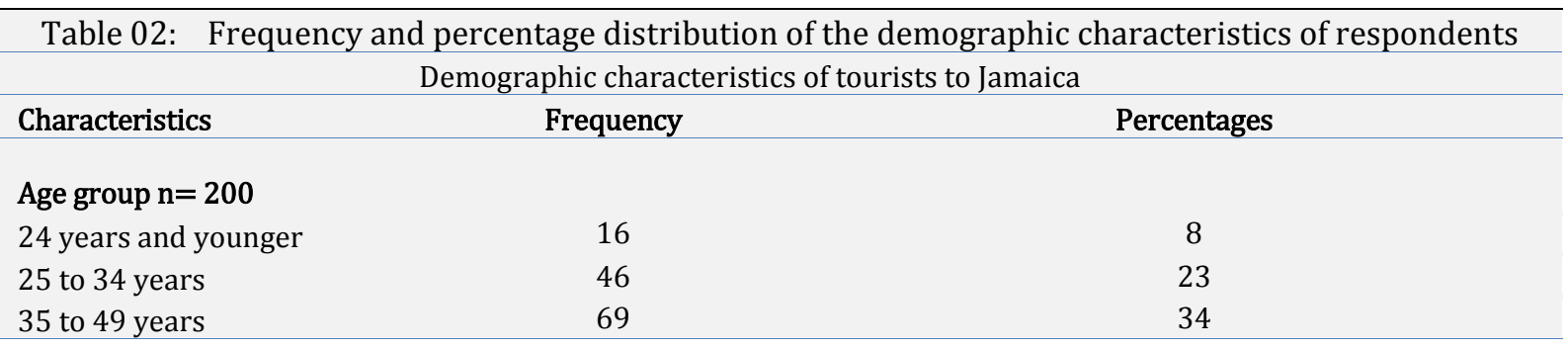




\begin{tabular}{|c|c|c|}
\hline 50 to 64 years & 56 & 28 \\
\hline 65 years and older & 13 & 6 \\
\hline \multicolumn{3}{|l|}{ Gender $n=200$} \\
\hline Male & 83 & 42 \\
\hline Female & 116 & 58 \\
\hline \multicolumn{3}{|l|}{ Country of Origin $n=99$} \\
\hline Bahamas & 2 & 1 \\
\hline Canada & 54 & 27 \\
\hline Europe & 53 & 27 \\
\hline Jamaica & 13 & 6 \\
\hline St. Vincent & 2 & 1 \\
\hline USA & 75 & 38 \\
\hline \multicolumn{3}{|l|}{ Employment Status $n=200$} \\
\hline student & 22 & 11 \\
\hline Self employed & 16 & 8 \\
\hline Employed full- time & 117 & 59 \\
\hline Employed part- time & 15 & 8 \\
\hline Unemployed & 5 & 2 \\
\hline Retired & 22 & 11 \\
\hline \multicolumn{3}{|c|}{ Gross monthly income \$US $n=138$} \\
\hline Under US $\$ 25,000$ & 102 & 74 \\
\hline US $\$ 25,100$ to US $\$ 49,900$ & 12 & 9 \\
\hline US $\$ 50,000$ to US74,900 & 9 & 7 \\
\hline US $\$ 75,000$ to US $\$ 99,900$ & 6 & 4 \\
\hline US\$100,000 and over & 9 & 7 \\
\hline
\end{tabular}

Regarding travel characteristics, most tourists travelled for rest and relaxation (59 per cent) while others came to visit friends and family (17 per cent), for business (10 per cent) and for weddings ( 7 per cent).

Only 2 per cent visited specifically for health and wellness, religious reasons and culture. The tendency towards rest and relaxation was synonymous with the main reasons for wellness travel and with the preferred wellness expectations. Travel for weddings was expected as local and international travellers gravitated towards resort locations for this purpose. This finding also implied that tourists do respond to the market and that a demand potentially exists for retirees and the youth market.

Of those who travelled with others on their visit, approximately 53 per cent had partners accompanying them and 21 percent were accompanied by family and relatives; 12 per cent were travelling alone. Those accompanied by co-workers and business partners represented were 3 and 2 percent respectively. Given the age ranges, the wellness market can potentially cater to families.

Most respondents spent less than one week on the island ( 72 per cent), 8 per cent spent between 1 and 2 weeks, 6 per cent spent 2 to 3 weeks and only 4 per cent spent more than 3 weeks.

\subsection{Research question 1 - How important is wellness to tourists in Jamaica?}

Research Hypothesis 1-Wellness is very important to tourists in Jamaica.

The findings presented in Table 3 confirmed that a concern for wellness did not depend on socio demographics profiles. Thirty six per cent of the respondents were engaged in a healthy lifestyle; 25 per cent were concerned about wellness; 21 per cent were somewhat concerned about wellness; and 16 per cent had no concern for wellness. The findings also suggest that wellness mattered as a combined 83 per cent of respondents were concerned, somewhat concerned about wellness or engaged in a healthy lifestyle.

Table 03: Frequency and percentage distribution of the importance of wellness to tourists' in Jamaica Attitude to wellness $\quad$ Frequency Percentage $\mathrm{N}=200$ 


\begin{tabular}{lcc} 
Concerned about wellness & 53 & $25.5 \%$ \\
Somewhat concerned about wellness & 42 & $21 \%$ \\
Engaged in a healthy lifestyle & 73 & $36.5 \%$ \\
No concern for health and wellness & 32 & $16 \%$ \\
Total & 200 & $100 \%$ \\
\hline
\end{tabular}

The findings also show that wellness was important to mature adults (35 - 49 years) most of whom were employed and were accompanied by someone. The respondents in the 25 - 34 years age group (41 per cent) were more often engaged in a healthy lifestyle. Those who were more concerned with wellness were in 35-49 years age group (34 per cent). Those who were somewhat concerned about wellness were 24 or younger (31 per cent) while most of those with no concern for wellness were in the $50-64$ age group (25 per cent). The Pearson's chi square $\chi^{2}(2)=13.219, \mathrm{p} 0>.05$ indicated that the statistical relationship between respondents age and the concern for wellness was not significant. Most of respondents were not averse to a packaged wellness vacation or online bookings. These results were expected as this researcher believes that working age adults would consider a wellness vacation, as they can better relate to its benefits.

\subsection{Research question 2- How important are wellness amenities and services to tourists in Jamaica?}

Research Hypothesis 2-Wellness amenities and services are important to tourists in Jamaica.



\section{Wellness remedies}

When asked to rate their preference for natural remedies, 82 per cent of the respondents rated water as the most important followed by air (80 per cent), rest (74 per cent), diet / healthy nutrition (65 per cent), sunshine (62 per cent) and exercise (60 per cent). 
The top three preferred wellness competencies were health care professionals and medical treatment (49 per cent), beauty care (23 per cent) and healing therapies 20 per cent. By contrast, 29\% rated individual care and wellness counselling as not being important.

\section{Mind therapy}

The respondents also reported preferences for certain mind therapies and the top three were relaxation (62 per cent) recreation (45 per cent) and prayer (35 per cent).

\section{Other activities}

The top three preferred activities were nature experiences (29 per cent), the pursuit of several activities (21 per cent) and community involvement (16 per cent). Identifying tourists' preferences can potentially assist in repositioning products in the wellness tourism sector. Park and Yoon (2009) maintain that tourists are motivated by relaxation away from the ordinary.

\section{Wellness Amenities}

Table 5 represents the ratings for wellness amenities. However to simplify the analysis, the table reflects the extremes from the Likert scale i.e. very important and not important. The wellness amenities that were deemed important included non-smoking areas (60 per cent), the gym (31 per cent), massage facilities, (25 per cent), swimming pool (26 per cent) and whirlpool and sports facilities (20 per cent); however, sauna (39 per cent), a solarium (38 per cent) and steam baths (36 per cent) were in the top three amenities that were deemed not important. These results were validated by the literature and were synonymous with the general findings about wellness segments, levels of concern for wellness, age groups and preferred accommodation for wellness vacation. Among those that were not important were health lectures, cooking demonstration, pampering, culinary tours, spiritual retreats, saunas, solariums and steam baths. The responses appear contradictory but the researcher believes that these responses were based on the tourists' experiences at their place of accommodation. Generally, when compared with the literature, the findings suggest that those services and amenities that were rated not important were associated with the more developed wellness markets.

Table 05: Frequency and percentage distribution of the wellness amenities preferred by tourists

\begin{tabular}{|c|c|c|c|c|c|}
\hline $\begin{array}{r}\text { Frequency of amenities } \\
\text { that were VERY } \\
\text { important }\end{array}$ & $\%$ & $\mathbf{N}$ & Wellness Amenities & $\begin{array}{l}\text { Frequency of amenities that } \\
\text { were NOT important }\end{array}$ & $\%$ \\
\hline 23 & 11.5 & 200 & Steam baths & 73 & 36.7 \\
\hline 19 & 9.5 & 200 & Sauna & 78 & 39 \\
\hline 11 & 5.5 & 199 & Solarium & 77 & 38.7 \\
\hline 41 & 20.5 & 198 & Sports facilities & 33 & 16.7 \\
\hline 63 & 31.5 & 200 & Gym & 21 & 10.5 \\
\hline 49 & 24.6 & 196 & Massage facilities & 27 & 13.8 \\
\hline 125 & 62.5 & 200 & Non-smoking areas & 16 & 8 \\
\hline 40 & 20 & 200 & Whirl pool & 35 & 17.5 \\
\hline 52 & 26 & 200 & Swimming pool & 9 & 4.5 \\
\hline
\end{tabular}

Table 6 reflects responses about the preferred accommodation type for a wellness vacation. Most respondents preferred a hotel (64 per cent). Nineteen per cent preferred a villa while 10 per cent preferred a bed and breakfast. Only 4 per cent preferred a private home while 2 percent preferred a guest house.

Table 06: Frequency and percentage distribution of the wellness amenities preferred by tourists in Jamaica

\begin{tabular}{lrr} 
Preferred type of & Frequency & $\%$ \\
$\begin{array}{l}\text { accommodation for a wellness } \\
\text { vacation }\end{array}$ & & \\
\hline Hotel & 128 & 64.0 \\
Villa & 38 & 19.0
\end{tabular}




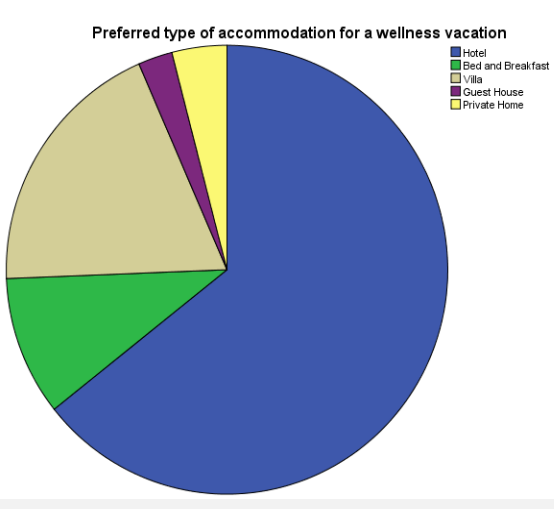

Bed and Breakfast

Private Home

Guest House
20

5
10.0

4.0

2.5

$\mathrm{N}=199$

\subsection{Research question 3 - Do tourists' in Jamaica has a strong preference for nature-based tourism?}

Hypothesis 3- Tourists in Jamaica do not have a strong preference for nature- based tourism

The attractive physical attributes that the respondents identified were among those generally associated with the Jamaican landscape. Most respondents reported being attracted to the warm weather (86 percent), the tranquillity (82 per cent), outdoor spaces (82 per cent) and the beautiful natural setting (81 per cent). By contrast, 61 per cent were not attracted to mineral baths and 50 per cent were not attracted to nature tours.

This result was expected as the Vision 2030 Plan alluded to Jamaica's low scores in this regard and the need to improve outdoor experiences. However, a plethora of lush plants (68 per cent), the unspoiled location (66 per cent) and waterfalls (63 per cent), were among the preferred attractions.

The findings show that despite the attractive physical features of Jamaica, most visitors prefer to stay at hotels. Therefore, tourists may have a strong preference for nature-based tourism but the available options and social challenges of the environment may not facilitate enough outdoor experiences ; thus the preferences reported suggests that the accommodation provided the guest with some nature- based experiences. Therefore, there is seemingly no catalyst for tourists to independently explore the natural physical aspects of the island. Hotels like firms based on the concept of the Resource Based View (RBV), (Gorodinia et al. 2012) will seek to maximise their profits through their goods and services. This researcher is inferring that nature-based experiences are brought to the tourists instead of the tourists being exposed to the nature based experiences. Policy intervention is proposed to facilitate more opportunities and protection for tourists. The researcher also concludes that the findings suggest that tourists have aligned themselves with the existing supply but if the destination attributes are pushed an alignment will also ensue.

\subsection{Research question 4 - What preferred natural resources are aligned with Jamaica's geographical} location?

When asked to indicate where they stayed in Jamaica, the respondents revealed the top three locations: Montego Bay (44 per cent), Ocho Rios (18 per cent) and Negril (17 per cent). Less than 10 per cent of respondents stayed in Kingston ( 9 per cent), the South Coast and Runaway Bay (5 per cent) and Portland (1 per cent).

The results were expected as Montego Bay, Ocho Rios and Negril are among the more popular resort areas. However, Runaway Bay, Portland and Trelawny do not have as many hotels. Based on the geographical attributes, the preferences for these locations appear more aligned with what is generally attractive and less aligned with what is preferred for a wellness vacation.

A cross-tabulation was performed for the accommodation type for a wellness vacation and geographical locations at the time of visit. All the respondents who stayed in Trelawny, Lucea and Portland had a strong preference for hotels for a wellness vacation followed by those who stayed in Ocho Rios (70 per cent), Negril (66 per cent) and Montego Bay (63 per cent).

Of those who preferred a bed and breakfast accommodation, 36 per stayed on the South Coast followed by those percent who stayed in Kingston (28 per cent), Ocho Rios (12 per cent), and Montego Bay (6 per cent). The Pearson chi square $\chi^{2}(2)=33.589, \mathrm{p} 0>.05$ indicated that the statistical relationship was insignificant. 
The respondents who stayed in Runaway Bay (30 per cent) preferred villas for a wellness holiday compared with those in Negril (24 per cent) and Montego Bay (19 per cent). Guest houses were preferred by the respondents who stayed in Kingston (6 per cent), as well as those who stayed in Negril and Ocho Rios (3 per cent). These tourists who preferred a private home experience ( 9 per cent) were among those who stayed in Montego Bay. These results were expected as there were fewer hotels in the more rural areas of the South Coast and Kingston and more hotels in the resort areas of Ocho Rios and Montego Bay. Additionally, the results indicate that the choice of accommodation were generally concerned the benefits associated with the facility not the geographical location. For instance, Montego Bay, Negril and Ocho Rios are more urbanised and have some of Jamaica's most prominent hotel brands. In this researcher's view, these facilities catered more to mass tourism and the general wellness expectations of their undemanding guests.

With regards to the respondents' willingness to recommend the location, 70 per cent would consider recommending the location at which they stayed. Thirty- nine per cent would consider a wellness package while sixty six percent would book their vacation on line.

The physical attributes were also aligned with some locations at the time of the visit to Jamaica. A crosstabulation of the physical attributes of the location and the geographical location at the time of visit showed that there is a statistical relationship between the physical attributes and the geographical location.

The tourists who stayed in Lucea, Trelawny, Runaway Bay and the South Coast all stated that they preferred the lush plants, pristine waters, beautiful natural setting, unspoiled location and outdoor spaces.

Most respondents who stayed in Portland did not align the location with preferred natural attributes. These results were unexpected as Portland is known for its lush landscape. This finding may be attributed to the fact that most of these respondents were staying at a hotel and may have based their evaluation on their actual experience. Those who stayed in Negril, Montego Bay and Ocho Rios preferred lush plants, pristine water, waterfalls, and warm weather, outdoor space and nature tours. The respondents who stayed in the South Coast preferred the tranquillity, lush plants, outdoor spaces, and beautiful natural setting while those in Kingston preferred the tranquillity and warm weather.

5.06 Research question 5 - What wellness attributes of the location are attractive to tourists in Jamaica?

The location's top three attractive attributes were the opportunity provided for rest (82 percent), the type of accommodation (78 per cent) and the quality of the amenities (71 per cent). Other attractive attributes as pull factors included the friendliness of the staff (76 per cent), the qualifications of the staff (74 per cent), and accessibility of the location ( 73 per cent) customer service ( 73 per cent), room quality, affordability and personal safety (72 per cent) respectively. Those that were not attractive included wellness treatments (74 per cent), sports facilities (73 per cent), shopping possibilities (63 per cent) and natural resources (56 per cent). The attributes that were not attractive, were not always part of the typical tourist experience which could explain these findings.

\subsection{Summary of research findings}

In summary, the findings and the answers found to the research questions 1, 2 and 3 were synonymous with those in the literature review. Firstly, this study hypothesized that wellness was not very important to tourists; this was rejected as wellness mattered to a combined 83 per cent of tourists. Secondly, in responses to research questions 2 and 3, the respondents revealed that wellness services and amenities are very important and that tourists in Jamaica do not have a strong preference for nature- based tourism.

Among the unexpected results is the low number of retirees who visited even though the wellness preferences of this group's wellness preference were aligned with most of the offerings in Jamaica. The amenities and services that were not preferred for example saunas and solariums were specialized amenities and services that were characteristic of the more developed wellness markets but they were not as popular in Jamaica. However, a preference for swimming pools was an expected preference for all wellness users. The low preference for mineral baths was unexpected given the uniqueness of Jamaica's therapeutic waters. Low preferences were also received for culinary tours, community involvement and the pursuit of multiple activities; as such the National Development Plan mentions that these areas were in need of improvement. Finally, despite the reported attractiveness of the locations' physical attributes, most respondents preferred to stay in hotels. They also indicated their willingness to recommend the location as a wellness destination, and most would consider a wellness package and book the location on-line. Forty per cent of the respondents did not know whether they 
would consider a wellness package; and in the researcher's view, this finding indicates that if wellness packages were effectively marketed, they could facilitate a more decisive response.

\subsection{Conclusion and policy implications}

The recommendations and conclusions will be discussed in relation to the findings of this study and the areas prioritized in the Caribbean Spa and Wellness Strategy 2014- 2018. The major conclusions are presented as well as the ways that the study may inform policy and practices in wellness tourism. Finally, the study's limitations and suggestions for future research are presented.

The findings revealed that those visiting friends and relatives ( 6 per cent) and those accompanied by family and friends ( 21 per cent) may be a potential target for other tourism niches.

The choice of accommodation was not aligned with a strong preference for nature-based tourism. Nevertheless, 36 per cent of respondents preferred accommodations such as villas and guests houses. Tourists' preferences for the primary elements of rural tourism imply that nature-based tourists could be targeted and that packaged deals could be configured according to the diverse motivators. However, Pesonen and Komppula (2010) agree that more studies are still needed in this area.

The findings imply that new forms of tourism may help with the rebranding and repositioning of the market such that wellness tourism may be of more economic significance. The wellness product may also benefit from current trends particularly in spa tourism, which has the potential to provide 'wowing' experiences for the affluent tourist and the youth market.

Additionally, the trends are considering the needs of males and females and the market has the potential to cater to the needs of everyone. An evaluation of the preferences from a geographical perspective showed that most destinations like firms utilized their unique attributes to gain competitive advantage. The country also has several other unique advantages; as such a significant focus on these advantages will enable the country to cater to different types of wellness seekers.

A focus on nature base and/ or rural tourism presents many opportunities for wellness, which have not been thoroughly explored in Jamaica. Among them are eco-tourism, culinary tourism and heritage tourism; segmentation could therefore be based on benefits required (Pesonen and Komppula 2010, 152). Valuable opportunities for cultural awareness exist for boutique hotels and the communities in which they are located.

Policies may be enacted to align vocational training system and tourism marketing efforts with international standards. The unique wellness preferences may also inform a national policy for wellness wherein 'new forms' of tourism and non-seasonal wellness tourism niches may be developed to highlight the island's beautiful natural setting and its culture and so provide more opportunities.

Tourists that are motivated by these factors are arguably potential consumers of wellbeing products and services (Pesonen \& Komppula, 2010). This study is expected to enable infrastructural development and a reallocation of private and public resources and a strategic shift towards the construction of accommodations around naturally occurring springs, heritage sites, historic buildings and unexplored natural highlights. Emphasis in these areas will subsequently support workplace wellness and primary health care.

\subsection{Limitations of the study}

As in the case with any other study, this one had limitations in terms of the availability of the literature on wellness tourism in Jamaica. The concept is fairly new and many findings were based on strategies and work plans.

Secondly, most case studies on wellness tourism relates to spas (Pesonen \& Komppula, 2010). Thirdly, the survey instrument did not capture all wellness preferences as choices. However, it captures the more popular preferences and those that were relevant to this study. Fourthly, the study assumes that the responses on the questionnaire were truthful and that respondents correctly reported their annual gross income.

Wellness tourism was not a core business for many hotels therefore the preferences among wellness guests in these hotels could not form part of the sample. At the time of the study, a second survey instrument was administered among the registered hotels in Jamaica. Email contact was made with 200 registered hotels across the island to ascertain how to best administer an online survey. One hundred and eighteen questionnaires were 
sent electronically to front desk and reservation personnel at all hotel types in the six resort areas. Two reminders were sent over a period of 4 weeks; however, only 4 of 118 responded. Fortunately, these limitations did not affect the conclusion of the study.

\subsection{Direction for further research}

The Service Sector and Expansion Plan (JAMPRO, 2013) acknowledged that the economic contribution and impacts are not well known for wellness tourism as there is no income statistic or GDP for the sector's activity. Therefore, research is needed on the economic impact of wellness tourism. Further research will also be needed on how to best to align Jamaica's vocational training system with that of international certification programmes. There is also a need to assess Jamaica's current position as it relation to wellness tourism. There are issues affecting occupancy in rural resort areas, as such empirical data are needed with regard to the ways in which nature-based tourism can be strengthened. Additionally, further studies may support a major distinction between tourism in areas other than Montego Bay, Negril and Ocho Rios. The public also needs to be educated about research findings relating to Jamaica's wellness tourism industry.

\subsection{Recommendations}

The primary recommendation arising from this study concerns promoting Jamaica's authentic experiences (Conway \& Timms, 2010).

\subsection{Improving the wellness product and capacity}

To facilitate improvements in wellness, Jamaica's wellness tourism brand will need to highlight both its culture and natural resources and to target those in the higher socio economic group (Sheldon \& Park, 2008). The product can be sustainable if it is strongly linked to tourists' emotional and spiritual needs and Jamaica uniqueness. The product can be packaged so that the tourists have the opportunity to enjoy both brands at the hotels or either brands at strategic accommodations; using the present brand, hotels may also use the benefits of the geographical location to facilitate well-being among different types of wellness guests (Lea, 2006). In doing so, hotels will continue to be the most in demand accommodation given their ambience, safety, amenities and convenience. However, smaller hotels may be improved to satisfy these guests in an atmosphere that highlights mineral baths, waterfalls, the beautiful natural setting, the unspoiled location and historical sites. Such attractive may be creatively highlighted using social media, websites, promotions and packaged deals.

From the perspectives of complementary and alternative medicine, Health tourism may also be creatively incorporated into the framework for tourists in 50 years and older age group.

The authenticity of the Jamaican wellness experience may be enhanced through the creative use of Jamaican foods. Jamaican herbs and spices may also be used and dishes may be customized and guided by healthy food combinations for those with discriminating eating patterns and diets. The researcher is of the view that the allinclusive concept does not support correct food combinations or sustainable wellness habits and so wellness facilities could set some precedence.

Kennett-Hensel et al. (2010) believes that there is also a strong demand for eco-tourism and cultural tourism. Accommodations may be positioned around natural springs and terrains that facilitate spiritual retreats for environment enthusiasts and fitness conscious travellers.

Communities may also be more actively engaged in the management of historical relics and value- added products. Once standards are met, Jamaican products made from neutraceuticals may also be used and sold at these accommodations and this may also enhance community tourism. The east coast can also facilitate slower forms of tourism such as farm tourism.

Despite the rural settings, current wellness trends can be incorporated into all types of accommodations, such that the tourist can assist as co-designer and co-marketer. Guest evaluation should also be mandatory so that the industry becomes more data driven. Small heritage galleries can also be established at some accommodation to build cultural awareness.

For some, wellness does not necessarily mean expensive amenities; instead it means the creative use of the inexpensive resources such as rest, exercise, diet, relaxation, water, spiritual support, warm weather, excursion, lush landscape, herb gardens, unique Jamaican flavours and fragrances, indigenous materials and many others that our creative minds have not yet conceptualized. 


\subsection{Strengthening the capacity and professional resources}

Jamaica already has favourable rankings for policy rules and the prioritization of tourism; thus resort developers can use empirical evidence to create purpose built facilities that are as controlled as the all-inclusive hotels.

Public education will be critical; the social studies curriculum should highlight the country's history very early in the education process. Additionally, a lead agency or task force should be assigned to oversee the implementation of new strategies for the development of wellness tourism. In some cases, foreign direct investors (FDI) have been censured for improving the spa offering only and ignoring the authentic experience that those in the wellness market seek.

Hoteliers may need to take a vested interest through philanthropy and volunteer tourism to improve existing natural assets and to create economic linkages. Additionally, the state needs to continue upgrading the infrastructure systems (Vision 2030 Jamaica, 2010) and to allocate resources in areas where there is evidencebased research. These findings may also form the basis for business loans for wellness-centred improvements. Therefore, marketing strategies should focus on rebranding, as the market already exists.

\subsection{Establishment a policy and regulatory framework}

To facilitate sustainability, Jamaica will need to improve its attractiveness by aligning its professional and marketing needs with international standards (Obradović, 2007) and to create a blend of its unique culture and nature resources (Sheldon \& Park, 2008) . In this regard, the capacity and curriculum of the country's leading tourism and spa management institutions will need to be strengthened.

Improvements in wellness tourism will require decisive action as the industry is in its infancy. The Tourism Product Development Company (TPDCO) should continue its goal of improving natural assets. The country also need to manage the propensities of negative externalities as failure to do so will perpetuate the tourism leakage rate and negatively affect the tourism systems.

\subsection{Recommendations for policy and practice}

In terms of policy and practice, improvements should continue in the country's regulatory framework, infrastructure and business environment (Vision 2030 Jamaica, 2010) and governance (Sheldon \& Park, 2008). The Caribbean Export Development Agency and the Caribbean Spa and Wellness Association have developed a project to assist countries in the Caribbean including Jamaica, in the task of expanding and marketing its health tourism offerings (International Medical Travel Journal, 2010). Trade liberalization under the General Agreement on Tariffs and Trade (GATS) and the Caribbean Single Market and Economy (CSME) will enable greater access to external markets (Vision 2030 Jamaica, 2010; Sheldon \& Park, 2008). Additionally, human capital can facilitate knowledge transfer and proficiency in foreign languages (Vision 2030 Jamaica, 2010).

Other recommendations for the sustainability of the tourism product includes the establishment of a transparent framework for stakeholders involved in decision making, the strengthening of the local government and partnerships between the public and private sector (Vision 2030 Jamaica, 2010)

Wellness tourism may also be encouraged among Jamaican who enjoy their vacation experiences in the island's tourism and hospitality sector. The resulting benefits may include a more productive and healthy workforce and increased revenue for the tourism sector.

In summary, this study is expected to contribute to the development of future wellness tourism products. To do so, the findings should inform national certification programmes and universities wherein academic facilitators will seek to encourage graduate research in tourism niches. Wellness practitioners are also expected to benefit as they continue to seek best practices. Finally, each wellness provider should be guided by a unique standard for business excellence and also to practice wellness in his /her personal life.

\section{References}

Benge, S. (2014, December 22). Healing Sources: Spa and wellbeing from the Baltic to the Black Sea. In amazon.com. Retrieved April 22, 2015, from http://www.amazon.com/Healing-Sources-WellbeingBaltic- 
Bennett, M., King, B., \& Milner, L. (2004). The health resort sector in Australia: A positioning study. Journal of Vacation Marketing, 10(2), 122-137.

Brown, G., Howat, G., \& Voigt, C. (2011). Wellness tourists: in search of transformation. Tourism Review at AIEST - International Tourism of Scientific Experts in Tourism, 66(1/2), 16-30.

Chen, C., Chen, S., \& Lee, H. (2011). The destination competitiveness of Kinmen's tourism industry: exploring the interrelationships between tourist perceptions, service performance, customer satisfaction and sustainable tourism. Journal of Sustainable Tourism, 19(2), 247-264.

Chen, J., Huan, T. C., \& Prebensen, N. (2008) Determining the motivation of wellness travellers. Anatolia: An International Journal of Tourism and Hospitality Research, 19(1), 103-115.

Cohen, S., Prayag, G., \& Moital, M. (2014). Consumer behaviour in tourism: Concepts, influences and opportunities. Current Issues in Tourism, 17(10), 872-909.

Conway, D., \& Timms, B. F. (2010). Re-branding alternative Tourism in the Caribbean: The case for 'slow tourism. Tourism and Hospitality Research, 10(4), 329-344.

Dennick, R., \& Tavakol, M. (2011). Making sense of Cronbach's alpha. International Journal of Medical Education, 1(2), 53-55.

Francis- Lindsay, J. (2009). The Intrinsic Value of Cultural Heritage and its Relationship to Sustainable Tourism Development: The Contrasting Experiences of Jamaica and Japan. Caribbean Quarterly, 55(2), 151-167.

Gorodnia, D., Lester, J., \& Pearcy, D. (2012). Using The Resource-Based View To Explore The Jamaican Health tourism sector as a service: A preliminary examination. Journal of Business Case Studies, 8(3), 1-10.

Heung, V. C., \& Kucukusta, D. (2013). Wellness tourism in China: Resources, development and marketing. International Journal of Tourism Research, 15, 346-359.

Jamaica Economic and Social Survey 2013. (2014, April). The Planning Institute of Jamaica, 192-199

Kennett- Hensel, P. A., Sneath, J. Z., \& Hensel, P. J. (2010). Developing sustainable tourism: Managers' assessment of jamaica's ten-year master plan. International Journal of Culture, Tourism and Hospitality Research, 4(2), 143-156.

Lea, J. (2008). Retreating to nature: rethinking 'therapeutic landscapes. Area, 40(1), 90-98.

Mak, A., Wong, K. K., \& Chang, R. C. (2009). Health or self-indulgence? The motivations and characteristics of spagoers.International Journal of Tourism Research, 11, 185-199.

Metapirak, Y., \& Siriphannapirat., G. (2012). The effect of health \& wellness resort attributes on customer satisfaction and post purchase behavioural intentions. 18th International Business Conference, Nevada, USA, 3-17.

Mueller, H., \& Kaufmann, E. L. (2001). Wellness Tourism: Market analysis of a special health tourism segment and implications for the hotel industry. Quelle: Journal of Vacation Marketing, 7(5), 5-17.

Obradović, M. (2007). Wellness- The challenge of the XX1 century. Selective Tourism, 1(1), 51.

Pitter, V. (2005). Cultural tourism: Its potential for growth and development In Jamaica's tourism sector (Master's thesis).

Pesonen, J., \& Komppula, R. (2010). Rural wellbeing tourism: Motivations and expectations. Journal of Hospitality and Tourism Management, 17(1), 150-157.

Ravichandran, S., \& Suresh, S. (2010). Using wellness services to position and promote brand India. International Journal of Hospitality \& Tourism Administration, 11, 200-217.

Sheldon, P. J., \& Park, S. (2008). Sustainable Wellness Tourism: Governance and Entrepreneurship Issues. Acta Turistica,20(2), 145-254.

Sheldon, P. J., and Sun-Young, P. (2008). Sustainable wellness tourism: Governance and entrepreneurship issues. Acta Turistica, 20 (2), 145-254.

Yoon, Y., \& Muzaffer, U. (2005). An examination of the effects of motivation and satisfaction on destination loyalty: a structural model. Tourism Management, 26(1), 45-56. 